\title{
La muerte como creación. La interiorización vitalista de la muerte en la vida en la filosofía de Ortega y Gasset
}

Death as Creation. The Vitalist Interiorization
of Death in life in Ortega y Gasset's Philosophy

ANTONIO GUTIÉRREZ POZO

Universidad de Sevilla (España)

Recibido: 14.07.2019

Aceptado: 13.12.2019

\section{RESUMEN}

El problema de la muerte resume las grandes líneas de pensamiento de la filosofía de Ortega. De hecho, la idea de la muerte lleva consigo una ciencia, una metafísica, una psicología etc., o sea, una idea de la cultura en general. Así, la pregunta por España, un asunto filosófico fundamental para Ortega, implica la cuestión de la muerte. La muerte según Ortega no es un simple elemento exterior de la vida sino un elemento interior y constitutivo de la naturaleza de la existencia. Pero contra el existencialismo Ortega no incorpora la muerte en la vida desde la idea de la muerte como lo esencial, como horizonte de sentido de la existencia, sino, en clave vitalista, como consecuencia de una vida plena y heroica. Esto es la muerte como creación de vida y no como a priori de la existencia.

\section{PALABRAS CLAVE \\ ORTEGA; MUERTE; VIDA; VITALISMO; CREACIÓN; \\ HUMANIZACIÓN}

\section{ABSTRACT}

The problem of death summarizes the main lines of thought of Ortega's philosophy. In fact, the idea of death carries with it a science, a metaphysics, a psychology, etc., that is, an idea of culture in general. Thus, the question about Spain, a fundamental philosophic matter for Ortega, implies the question of the death. According to Ortega, death is not a simple external element of life but it is an internal and constitutive element of the nature of existence. However, against existentialism Ortega does not incorporate death into life from the idea of death

Claridades. Revista de filosofía 12/1 (2020), pp. 107-135

ISSN: 1889-6855 ISSN-e: 1989-3787 DL.: PM 1131-2009

Asociación para la promoción de la Filosofía y la Cultura (FICUM) 
as an essential idea, as the horizon of meaning of the existence but, in vitalist terms, as consequence of a full and heroic life. This is death as creation of life and not as a priori of existence.

\section{KEYWORDS}

\section{ORTEGA; DEATH; LIFE; VITALISM; CREATION; HUMANIZATION}

\section{INTRODUCCIÓN}

Aunque eS CIERTO que «en la actualidad, el problema de la muerte y la inmortalidad ha desaparecido en gran medida de los debates filosóficos» debido a que la filosofía cada vez más se reduce a cuestiones de lógica, teoría científica o análisis del lenguaje ${ }^{1}$, postergando al ámbito del sentimiento subjetivo o de la poesía las cuestiones fundamentales, las cuales por supuesto ni serían objeto ni tendrían cabida en la filosofía cientifica, a pesar de ello, «la muerte es una de las cuestiones filosóficas más importantes» ${ }^{2}$. Y lo es porque concentra en ella los dos grandes núcleos argumentales que constituyen el fondo del saber filosófico: la antropología, la pregunta por el ser humano, y la metafísica, la cuestión del ser. La pregunta por el ser humano que según Kant reune todas las preguntas fundamentales de la filosofía, y el problema del ser se fusionan en la cuestión de la muerte, en el supremo misterio del paso del ser al no ser, pues ante este extraordinario enigma del dejar de ser, que tanto nos abruma y desafía nuestra propia conciencia, el ser humano toma conciencia de la esencia de su humanidad como ser que se admira de que haya ser y de que desaparezca absolutamente. Al tiempo, la muerte interroga al ser humano sobre la naturaleza de su propia humanidad y su destino, y plantea esencialmente el secreto del ser. Para ser fiel al radicalismo que define su pensamiento ${ }^{3}$, Ortega no podía evitar medirse con este arcano de la muerte. No obstante, si en otros pensadores cercanos a su contexto filosófico, cultural e histórico, como Unamuno o Heidegger, el problema de la muerte muestra una relevancia bien explícita ${ }^{4}$, en la obra de Ortega en cambio parece resultar ciertamen-

1 Scherer, G., «Philosophie des Todes und moderne Rationalität», en Der Tod in Dichtung, Philosophie und Kunst, H. H. Jansen (Hg.), Darmstadt: Steinkopff, 1989, 505-521, p. 507.

2 Schumacher, B. N., Der Tod in der Philosophie der Gegenwart, Darmstadt: Wissenschaftliche Buchgesellschaft, 2004, p. 245.

3 Cfr. Cerezo, P., La voluntad de aventura. Aproximamiento crítico al pensamiento crítico de Ortega y Gasset, Barcelona: Ariel, 1984, pp. 302-315.

4 Sólo tenemos que recordar el conocido «hambre de inmortalidad» unamuniano, el 
te un asunto menor con no demasiada trascendencia. Esta apariencia ha penetrado en la interpretación de su pensamiento hasta el extremo de que se ha asegurado que «para Ortega el nacer y morir representa sólo un automatismo biológico (...) carente de significado ontológico» ${ }^{5}$. Absolutamente opuesta sería entonces la posición de Heidegger, que concede a la muerte la máxima importancia ontológica al cifrar en ella la afirmación de la finitud radical del ser humano ${ }^{6}$. Nuestro entendimiento de esta cuestión sin embargo es bien distinto. Contra aquella comprensible apariencia, en este trabajo intentaremos exponer el valor filosófico central que tiene la idea de la muerte en la obra de Ortega, tanto que es ella también, a pesar de la tesis de Regalado, la que da forma al alma de la finitud en su filosofía, aunque en una dirección distinta —opuesta — a la versión heideggeriana. La consecuencia de esta exposición no puede ser otra que animar a futuros trabajos sobre esta materia, ya que el breve espacio de este artículo ni puede -ni quiere- abarcar todos los ricos matices que presenta el problema de la muerte en Ortega, y porque además dicha cuestión no ha sido tratada como merece en la bibliografía especializada. Desde luego nunca monográficamente sino sólo de forma indirecta, de camino a otros temas de la filosofía orteguiana. Las dos razones que justifican de entrada el calado filosófico que tiene el concepto de la muerte en el pensamiento de Ortega son, al tiempo, los motivos filosóficos que explican su interés por la muerte y que le empujan a filosofar sobre ella. El primero de ellos tiene un carácter más vivencial y su contenido es la cultura española, dando por sentado que España para Ortega es también y muy principalmente un problema filosófico. El segundo presenta una naturaleza más estrictamente teórico/filosófica.

«inmortal anhelo de inmortalidad», y su lógica y confesada consecuencia: «No quiero morirme, no, no quiero ni quiero quererlo», Unamuno, M. de, Del sentimiento trágico de la vida (1912), Obras completas, t. X, Madrid: Fundación José Antonio de Castro, 2009, pp. 285, 305, 311, 450. El propio Ortega presenta a Unamuno como un gran español, un gran celtíbero, porque "hizo de la muerte su amada», su "perenne amiga-enemiga», Ortega y Gasset, J., «En la muerte de Unamuno» (1937), en OC V, Madrid: Fundación Ortega y Gasset/Taurus, 2006, p. 409. Y en Heidegger el Sein zum Tode, como auténtica posibilidad del Dasein, protagoniza el primer capítulo de la segunda sección (Dasein und Zeitlichkeit) de Sein und Zeits, Heidegger, M., Sein und Zeit (1927), en GA 2, Frankfurt a. M. Klostermann, 1977, \46-53, pp. 314-354.

5 Regalado, R., El laberinto de la razón: Ortega y Heidegger, Madrid: Alianza, 1990, p. 227. 6 Ibidem. p. 230. 


\section{LA MUERTE Y ESPAÑA. LA MUERTE, COMPENDIO FILOSÓFICO}

El primer motivo que impulsa a Ortega a pensar la muerte es su preocupación por España, preocupación que no sólo tiene un origen sociohistórico y político. Aunque ciertamente «el español que pretenda huir de las preocupaciones nacionales será hecho prisionero de ellas diez veces al día y acabará por comprender que para un hombre nacido entre el Bidasoa y Gibraltar es España el problema primero, plenario y perentorio», aunque «el español necesita, pues, ser antes que nada político» ${ }^{7}$ y España sea ante todo una urgencia política a la altura de 1910, para Ortega lo español es además una categoría filosófica crucial con valor objetivo universal. Esta autoconciencia filosófica española no caracteriza exclusivamente a Ortega sino que, según Laín Entralgo, «el rasgo más significativo de nuestra historia intelectual contemporánea es este esfuerzo doloroso e incesante por llegar a una definición del ser histórico de España o, al menos, a una interpretación adecuada y profunda de ese ser» ${ }^{8}$. Y esto se debe, en el caso de Ortega y muy brevemente a que, ante la crisis cultural y filosófica de final del s. XIX, producida por la dialéctica excluyente entre positivismo e idealismo culturalista, «España es una posibilidad europea»", es decir, una vía intermedia entre el materialismo apegado a las cosas tal y como se dan y el idealismo racionalista que construye las cosas idealmente en la cultura, mediación que desembocará en la racionalidad vital. Por eso es necesario pensar lo español y de ahí que Ortega formule la gran pregunta «dios mío, ¿qué es España?» justo en el centro vertebrador del libro (Meditaciones del Quijote) donde expone por primera vez su receta de salvación de la cultura europea -y de España-, la 'razón vital': «Esta misma oposición, tan usada hoy por los que no quieren trabajar, entre la razón y la vida es ya sospechosa. ¡Como si la razón no fuera una función vital y espontánea del mismo linaje que el ver o el palpar! $»^{10}$. Esta posibilidad europea de carácter raciovitalista que supone la cultura española está encerrada en el estilo del Quijote, un «guardián del secreto español», y por ello «si supiéramos con

\footnotetext{
7 Ortega, «La pedagogía social como programa político» (1910), OC, II, 2004, p. 89.

8 Laín Entralgo, P., «La spiritualité du peuple espagnol. Le temps et la présence de la mort», en VV. AA., Le temps et la mort dans la philosophie espagnole contemporaine, Toulouse: Edouard Privat, 1968, 15-28, pp. 17s.

9 Ortega, «España como posibilidad» (1910), OC, I, op. cit., 2004, p. 337.

10 Ortega, Meditaciones del Quijote (1914), OC, I op. cit., pp. 791, 784.
} 
evidencia en qué consiste el estilo de Cervantes, la manera cervantina de acercarse a las cosas, lo tendríamos todo logrado» ${ }^{11}$.

Ahora bien, pensar radicalmente la esencia de España supone para Ortega pensar la muerte porque ésta no sólo está muy presente en la vida española, sino que además interviene decisivamente en la constitución del ser español ${ }^{12}$. La idea de la muerte forma parte fundamental de la definición de la esencia de la cultura española. Esta cualidad diferencia la cultura española de la modernidad pues, en palabras de Laín Entralgo, y a pesar de la trascendencia filosófica del concepto de muerte, «el mundo moderno ha sido firmemente tanatófugo», es decir, huye de la muerte, evita considerarla, y «ha considerado la existencia humana según lo que ella pueda hacer en la vida, y no según la inamovible certeza de su esencial sumisión a la muerte» ${ }^{13}$. Por esta razón, cuando un moderno piensa la muerte lo hace al modo paradigmático de Montaigne, esto es, procurando que la propia meditación nos enseñe a no sobrevalorar la muerte y a desdeñarla sofocando el desasosiego y el miedo que nos produce la muerte y proporcionándonos de ese modo tranquilidad: «Uno de los principales beneficios de la virtud es el desprecio (mepris) de la muerte, medio que suministra (fournit) a nuestra vida una suave tranquilidad (molle tranquillité), dándonos el gusto puro y amable sin el que cualquier otra voluptuosidad se apaga» ${ }^{14}$. Apartándose de esta actitud tanatófoba moderna y en cierto modo anticipando el interés contemporáneo por la muerte, la «tanática España», desde Séneca a Ortega y Unamuno pasando por Manrique, Teresa de Jesús, Juan de la Cruz, Calderón o Quevedo, ha hecho de la muerte un tema muy español ${ }^{15}$. Esto se explica porque la cultura española ha entendido que la muerte forma parte de la vida, que la constituye esencialmente, de modo que no podemos pensar la vida sin la muerte. A lo largo de toda su obra el propio Ortega ofrece suficientes pruebas de que es muy consciente de ello. En efecto, si España ha considerado que la muerte constituye esencialmente a la vida es porque sabe cuál es «el acto vital más importante, que es aquel en que se

11 Ibid., pp. 790, 793.

12 Cf. Laín Entralgo, op. cit., p. 18.

13 Ibid., p. 22.

14 Montaigne, M. de, Les Essais (1580-1588), P. Villey (ed.), Paris: Quadrige/PUF, 1965, L. I, ch. xx, p. 82. Cf. Laín Entralgo, op. cit, p. 22.

15 Laín Entralgo, op. cit, p. 23. 
afronta la muerte» ${ }^{16}$. Y según Ortega lo sabe desde hace mucho tiempo, desde el origen de la cultura española: «Los celtíberos eran el único pueblo que vestía de negro y adoraba a la muerte» ${ }^{17}$. Desde su obra de juventud, Ortega ha tenido conciencia de que una clave de la cultura española ha sido bailar ante la muerte, es decir, no rehuirla, no eludirla. Esta actitud de arrostrar la muerte se manifiesta en la «regocijada danza de la Muerte que España va danzando siglos hace ${ }^{18}$. Ya dos años antes Ortega había expresado con claridad que no se puede entender el alma española sin su esencial relación tanatófila con la muerte, pues «somos desde siempre amigos de la muerte», tanto que «Ignacio de Loyola vio en la imagen de la muerte la llave que abría de para en par y cerraba firmemente nuestras almas ${ }^{19}$. Esto es lo que significa el toreo en la cultura española, «una danza, la danza ante la muerte, se entiende, ante la propia» ${ }^{20}$. Dado que la categoría de muerte pertenece a la comprensión (perspectiva) española de la vida y el mundo, Ortega entiende que España no puede ser entendida sin descifrar el enigma de la muerte, de donde se desprende que esta necesidad cultural es un motivo explicativo de su preocupación filosófica por la muerte.

Ahora bien, este vínculo esencial entre España y la muerte es presentado por Ortega como algo más que un tema para alcanzar la dimensión de vivencia. Y ello no sólo porque la muerte es, como para toda persona, una experiencia ${ }^{21}$, sino porque vivió de forma peculiar ese nexo de lo español y la muerte. Y es Heidegger el que nos da cuenta del alcance de esta vivencia. Tras la muerte de Ortega en 1955, Heidegger redactó una semblanza de su relación personal en los dos encuentros que mantuvieron. Del segundo

16 Ortega, Velázquez (1943-1950), OC,VI op. cit., 2006, p. 709.

17 Ortega, «En la muerte de Unamuno» op. cit., p 410.

18 Ortega, «Asamblea para el progreso de las ciencias» (1908), OC I op. cit.p. 184.

19 Ortega, «Paisajes ideológicos» (1906), OC VII, op. cit., 2007, p. 102.

20 Ortega, «Enviando a Domingo Ortega el retrato del primer toro» (1950), OC X op. cit., 2010, p. 333; Velárquez, op. cit., p. 653.

21 Tras la tragedia soportada por España con la Guerra Civil y su operación a vida o muerte de 1938 del aparato digestivo, Ortega confiesa haber vivido pendiendo de un hilo y haber superado esta situación gracias a la ilusión, verdadero motor de la acción humana: «He padecido miseria, he sufrido enfermedades largas de las que tratan de tú por tú a la muerte, y debo decir que si no he sucumbido en tanta marejada ha sido porque la ilusión de acabar esos dos libros [Aurora de la razón histórica y El hombre y la gente] me ha sostenido cuando nada más me sostenía», Ortega, Ideas y creencias (1940), OC V op. cit., p. 657. 
de ellos y tras la discusión pública oficialmente programada ${ }^{22}$, Heidegger dice que Ortega les habló de «un tema que ni estaba formulado ni previsto y que podía llevar el título de El hombre español y la muerte (Der spanische Mensch und der Tod). Ciertamente, sólo dijo aquello con lo que había estado familiarizado desde hacía mucho tiempo, pero cómo lo dijo nos reveló cuanto más adelantado estaba que sus cautivados oyentes en un campo (Bereich) que ahora ha traspasado» ${ }^{23}$. No hay prueba documental de esa intervención de Ortega pero sin duda parece estar muy cerca de un breve apunte de 1948 titulado El hombre español incorporado a Sobre una nueva interpretación de la historia universal ${ }^{24}$. No puede entonces resultar sorprendente que en el concepto orteguiano de la muerte perviva esta comprensión española de la muerte, ya que aquél ha sido pensado desde ésta. En ese breve texto de 1948 ya referido se subraya una determinada actitud existencial propia de la subjetividad española, que supone lógicamente una cierta disposición ante la muerte y que coincide con tesis fundamentales ya expuestas por Ortega a lo largo de su obra como el espíritu guerrero, la autenticidad o el carácter heroico. Lo esencial de este sujeto es no ya no tener miedo en determinadas situaciones vitales sino «no tener miedo a la vida», justo lo contrario del «ser cobarde ante el vivir mismo, es decir, sentirse incapaz de vivir, sentir terror a vivir si no se dan ciertas condiciones»; si este tipo de ser humano miedoso necesita una serie de requisitos para poder vivir, «el español no pone originariamente condición ninguna a la vida. Está dispuesto a vivir sin condiciones, ve la vida como una infinita desnudez, como una ausencia de todo y, sin embargo, eso no le produce ni angustia especial ni desánimo ni pavor. De aquí la famosa falta de necesidades del español ${ }^{25}$. Ortega presenta a San Francisco de Asís con su conocido yo necesito poco, y ese poco lo necesito muy poco, como mo-

22 Heidegger no dice la fecha pero pudo ser unos meses después de las conferencias de agosto de 1951 en Darmstadt, donde Heidegger presentó «Bauen, Wohnen, Denken» y Ortega «El mito del hombre allende la técnica». El encuentro concreto pudo ser una discusión pública que ambos pensadores mantuvieron en Bühlerhöhe y de la que Ortega hizo una posterior referencia, Ortega, «En torno al Coloquio de Darmstadt, 1951» (1952) (Borrador), OC X op. cit., p. 378.

23 Heidegger, M., «Begegnungen mir Ortega y Gasset» (1955), Aus der Erfahrung des Denkens (1910-1976), GA 13, 1983, op. cit.,1983, p. 129.

24 Ortega, «El hombre español», Sobre una nueva interpretación de la historia universal, OC IX, 2009 op. cit., pp. 1368-1371.

25 Ibid., pp. 1370 s. 
delo de humanidad del ser humano español, un ser humano que «no tiene última y efectivamente necesidades porque para vivir, para aceptar la vida y tener ante ella una actitud positiva no necesita de nada», hasta tal extremo - y esto es lo que más nos interesa— «no necesita de nada para vivir, que ni siquiera necesita vivir, no tiene últimamente gran empeño en vivir y esto precisamente le coloca en plena libertad ante la vida, esto le permite señorear sobre la vida» ${ }^{26}$. Ahora bien, la subjetividad que no necesita ni siquiera vivir, que no considera el perseverar en la existencia como valor supremo, es la única que tiene libertad para poder entregar la vida por una meta, incluso al precio de la muerte. Esta tesis contiene la clave esencial de la comprensión filosófica orteguiana de la muerte, la cual por tanto se forja en esta ligazón esencial entre el ser humano español y la muerte.

El segundo motivo que impulsa al pensamiento orteguiano de la muerte no es otro que el peso filosófico central que tiene este concepto. No es un simple asunto más de la filosofía sino una clave esencial, una consecuencia y por tanto un síntoma de todo un modo de pensar. Así lo sostuvo Santayana en 1913 cuando aseguró que «una buena manera de medir el calibre de una filosofía es preguntarle qué piensa sobre la muerte» ${ }^{27}$. El propio Ortega es consciente de ello al advertirnos de que «la idea de la muerte implica toda una biología, una psicología, una metafísica» ${ }^{28}$. Esto quiere decir que el concepto de muerte es una clave intelectual que compendia una filosofía entera. Lo que pensamos sobre la muerte es consecuencia de lo que pensamos acerca del resto de materias, de modo que la idea de la muerte concentra en ella misma toda una filosofía. Estudiar por tanto la noción de muerte de un pensador equivale tanto a pulsar todos los registros de su filosofía como a — sobre todo— sondear su fibra filosófica más íntima. Esto es lo que pretendemos hacer con Ortega, para el que sin duda la noción de muerte es piedra de toque donde se perfila su propia filosofía, un criterio de su calado filosófico. Por ello mismo, y como ya advertimos, es un nudo filosófico que merece más espacio del que podemos dedicarle en este trabajo.

26 Ibid., p. 1371.

27 Santayana, G., «The philosophy of M. Henri Bergson», Winds of Doctrine. Studies in Contemporary Doctrine (1913), en Selected Critical Writings of G. Santayana, v. II, N. Henfrey ed., London: Cambridge University Press, 1968, p. 154, 122-160.

28 Ortega, En torno a Galileo (1933-1947), OC VI op. cit., p. 416. 


\section{EL SENTIDO ESTÉTICO DEL MORIR}

Hacia el final de su trayectoria filosófica y tras haber respirado la atmósfera tanatófuga de la modernidad europea, escribe Ortega que «una de las grandes limitaciones, y aún deberíamos decir de las vergüenzas de las culturas todas hasta ahora sidas, es que ninguna ha enseñado al hombre a ser bien lo que constitutivamente es, a saber: mortal» ${ }^{29}$. El ser humano no sólo es naturalmente algo, lo que sea, sino que reflexiona sobre ello y crea una cultura desde la que vive aquello que en principio es espontáneamente. Esto es lo que significa decir que no sólo es naturaleza sino también e indisolublemente cultura. Por tanto, el ser humano no sólo es mortal sino que precisa de una cultura que lo eduque para vivir la mortalidad que es. Esa queja tardía de Ortega, por distanciada que pueda parecer, conecta con otro lamento muy propio de su filosofía más juvenil y configurador de su pensamiento: la cultura europea moderna se ha vuelto de espaldas a la existencia humana concreta y no educa para vivir, algo además que considera impropio de la 'alta cultura'. Aunque para cada uno su vida sea lo más importante, «de nada nos ocupamos menos que de esa vida nuestra» ${ }^{30}$. En efecto, la cultura europea ha progresado en el conocimiento y dominio del mundo y de la materia pero, al tiempo, «desatendía por completo el cultivo de otras zonas del ser humano que no son intelecto, cabeza; sobre todo, se dejaba a la deriva el corazón», lo que explica además «el desequilibrio que hoy padece el hombre europeo entre su progreso de inteligencia y su retraso de educación sentimental» ${ }^{31}$. Este intelectualismo ha llegado al extremo de apropiarse el término 'cultura' para atribuírselo en exclusiva a la inteligencia, a pesar de que, aclara Ortega, fue usado primero por Luis Vives «para significar con preferencia cultivo del corazón, cultura animi ${ }^{32}$. Europa ha estado dominada por dos corrientes de pensamiento que, a pesar de su aparente oposición, se han combinado perfectamente para relegar la vida personal e inmediata a segundo plano y arrojarla de la cultura: el idealismo y el positivismo, los cuales han dado lugar a una cultura, por un lado, de grandes ideas que, al margen de la existencia real de los individuos y de sus emociones, nos dejan fríos, y por otro lado, una cultura de medios,

29 Ortega, El hombre y la gente (1949-1950) (Notas), OC X op. cit., p. 491.

30 Ortega, «Azorín: primores de lo vulgar» (1917), El Espectador II, OC II op. cit., p. 294.

31 Ortega, «Corazón y cabeza» (1927), OC VI op. cit., p. 208.

32 Ibid., p. 208; Ortega, Juan Luis Vives y su mundo (1940), OC IX op. cit., p. 465. 
sin metas, lo que ha producido una brecha entre la cultura con sus frases y gestos, y la existencia real cotidiana ${ }^{33}$. Por tanto, la cultura moderna sólo se ha ocupado de las grandes cosas y ha dejado de realizar su función principal, que es atender, educar y orientar la vida humana real; ha olvidado la existencia personal y sentimental abandonándola a su propia inmediatez irreflexiva sin asistencia meditativa, sin disciplina. En esa cultura ha vivido y se ha formado Ortega según confiesa: «La época en que hemos sido educados ponía sus cinco sentidos y toda su atención en la política, o en la economía, o en la ciencia; sólo una cosa había en que no paraba mientes, sólo una cosa hacía sin intención y a la diabla. ¿Cuál?. Vivir» ${ }^{34}$. Unos años antes ya advirtió que «nada es tan ajeno a la conciencia superficial que hoy rige el mundo como estos afanes y cuidados propios a la cultura de la persona. En estos tiempos que cuentan con complicadas técnicas para todo, sólo se hace una cosa al buen tuntún: vivin» ${ }^{35}$.

Contra esta carencia de adecuada atención que le ha dispensado la cultura europea idealista/positivista y contra el olvido, la existencia humana necesita ser considerada por una nueva cultura como su objeto primordial. Ante la falta de cultivo, urge una cultura de la vida, volcada fundamentalmente sobre la vida personal, inmediata y emocional. Ortega ya había reparado en que «múltiples signos anuncian que los hombres van a corregir este olvido, y aplicarán sus mejores esfuerzos a hacer de sus propias vidas un edificio lo más perfecto posible» ${ }^{36}$. Pero este tratamiento de la vida humana, para que sea eficaz, debe ser respetuoso con su naturaleza fluida e inapresable, de modo que no puede administrarse -contra el racionalismo spinozista- more geometrico, sino más bien more artístico, como si la vida fuera una obra de arte que hay que cincelar y no un contenido matemático objetivable y calculable. En efecto, añade, «se inicia una nueva forma de la cultura -la vida selecta y armoniosa; despierta un arte nuevo: la vida como arte, el refinado sentir, el saber amar, y desdeñar, y conversar, y sonreir ...»; y este cuidado de la existencia humana característico de la nueva cultura posmoderna que está vislumbrando Ortega en el horizonte europeo es

33 Ortega, «Verdad y perspectiva» (1916), El Espectador I, OC II op. cit., p. 159; «Ideas sobre Pío Baroja» (1916), El Espectador I, pp. 228s; El tema de nuestro tiempo (1923), OC III op. cit., 2005, pp. 585s.

34 Ortega, «Para un museo romántico» (1921), El Espectador VI, OC II op. cit., pp. 626s. 35 Ortega, «Azorín: primores de lo vulgar» op. cit., p. 296.

36 Ortega, «Para un museo romántico» op. cit., p. 627. 
calificado por él mismo como «sentido estético del vivir» ${ }^{37}$. Esto quiere decir que la inobjetivabilidad de la vida humana efectiva, sus peculiares y sutiles registros, sólo pueden ser trabajados por una lógica delicada, es decir, estéticamente.

Ahora bien, ocuparse de la vida humana equivale a ocuparse de la muerte y ello no sólo porque le parezca a la conciencia natural que la muerte forma parte de la propia vida, tesis que para ser correctamente interpretada merece un examen más detenido, sino sobre todo porque decir que se estudia la naturaleza de la vida humana supone decir que se va a investigar la naturaleza del ser mortal. Habida cuenta de que vivir comprende esencialmente vivir la mortalidad que somos, la cultura del ser mortal que vergonzosamente nos falta no es sino esa misma cultura de la vida de la que ha carecido Europa. Esto significa que la actitud predominante en la modernidad burguesa europea ha sido evitar la muerte, no enfrentarla sino posponerla, actuar como si no existiera. En cierto modo, y aunque pudiera parecer lógico o natural que la tanatofobia moderna hubiera conducido a una cultura biófila, más bien ha sucedido que la tanatófuga modernidad ha producido una cierta cultura biófoba. Por esto, Ortega asegura que, «después de dos siglos de huir la muerte, hace falta fomentar el arte de morir» ${ }^{38}$. Esto significaría a su vez construir una cultura verdaderamente biófila. Lejos de eludir la muerte como si meramente fuera un hecho al margen del vivir, la cultura del ser mortal que reclama Ortega representa realmente la integración de la muerte en la propia existencia, que es lo que significa el arte de morir, cincelar o elaborar la muerte, convertirla en un arte. Finalmente también encontramos en Ortega un sentido estético del morir. La cultura del ser mortal por la que clama Ortega es el nombre que ha tomado en su obra de madurez su anterior afirmación del 'sentido estético del vivir', el cultivo del espíritu o cultura animi. Más adelante comprobaremos cómo este arte del morir resume ejemplarmente la posición fundamental de Ortega ante la muerte. Naturalmente, antes de hacer esa cultura del ser mortal, y para poder edificarla, Ortega necesita disponer de una idea de la muerte, y por ello él mismo, en vez de rehuirla, la encara teóricamente. Se trata, pues, de pensar la muerte no de temerla (Meditatio mortis no timor

37 Ibid.

38 Ortega, «Notas del vago estío» (1925), El Espectador V, OC, II op. cit., p. 548. 
mortis $^{39}$, pero - a diferencia de Montaigne — no para quitarle peso y despreciarla y conseguir así tranquilidad vital, sino para conocerla en su verdad. No se puede aprender a vivir en la mortalidad sin una previa noción de la muerte, cuyo análisis y despliegue desde la perspectiva orteguiana es el objeto de este trabajo.

\section{FILOSOFÍA DE LA EXTERIORIZACIÓN DE LA MUERTE}

Para entender la idea orteguiana de la muerte y su papel dentro de su pensamiento es menester situarla dentro de las distintas posiciones filosóficas fundamentales acerca de la muerte aclarando lo que tiene en común con ellas y lo que la diferencia. Para exponer dichas perspectivas o modos básicos de comprender la muerte planteamos este elemental esquema. Las comprensiones primordiales sobre la muerte se resumen en dos. La primera considera que la muerte está desintegrada o separada de la vida al reducirla a mero hecho externo, a límite final de la existencia. La comprende como un hecho exterior a la vida de la que entonces no formaría parte y, en consecuencia, como algo no actuante en la constitución de su naturaleza. Esta comprensión exterior de la muerte obedece a una actitud de huida y elusión de la muerte. La segunda, al contrario, no entiende la muerte como mero hecho final o cese de la existencia sino que la incorpora a la misma como nota clave interna y constituyente de su carácter. Esta comprensión interior de la muerte representa la otra actitud esencial ante el fenómeno mortal, la de integrarlo en el vivir mismo. Ahora bien, dentro de esta perspectiva hay, a su vez, dos formas de concebir la interiorización o incorporación de la muerte en la vida. Una, que denominaremos existencialista, la lleva a cabo primando la muerte, partiendo de que la muerte es lo sustancial, lo cual además puede hacerse bien a la manera de Heidegger, desde la angustia y el serpara la muerte, el Sein zum Tode, o bien al modo unamuniano, desde el ser contra la muerte que representa el hambre de inmortalidad y su voluntad de «no merecer la muerte, de hacer que nuestra aniquilación [y la nada], si es que nos está reservada, sea una injusticia» ${ }^{40}$. De corte más vitalista, la otra forma de incorporar la muerte en la existencia es primando la vida, desde el ser para la vida. Esta es la posición de Ortega. Dentro de

39 Ortega, «Algunas notas de José Ortega y Gasset» (1912-1915), Revista de Occidente, 156 (1994), 33-54, p. 53.

40 Unamuno, M. de, Del sentimiento trágico de la vida op. cit., pp. 494, 309,480, 483, 487. 
los límites de este trabajo desarrollaremos algo más este esquema general.

La muerte es un hecho, concretamente el que marca el final y la conclusión de la existencia. Pero lo que hace la comprensión exterior de la muerte es reducirla precisamente a ser puerta de salida de la vida y nada más. En este sentido, la muerte, interpretada como punto final y límite de la existencia, es algo exterior al vivir mismo, como si estuviera al margen de la propia vida. Tal vez el ejemplo más conocido e ilustre de esta filosofía de la exteriorización de la muerte es Epicuro, que escribe en su Carta a Meneceo (s.IVa.C.) que «la muerte, el más terrible de los males, no se relaciona con nosotros pues mientras estamos vivos no existe, y cuando ella es no existimos nosotros $»^{41}$. La muerte por tanto no significaría nada para nosotros, ni nos importa ni nos afecta, nada tiene que ver con nosotros, ya que mientras somos no hay muerte y cuando hay muerte no estamos ya presentes. Esta tesis epicúrea es la que asume también Montaigne al sostener que «la muerte no nos concierne ni muertos ni vivos (vif): vivos, porque existimos: muertos, porque no existimos» ${ }^{42}$. Esto quiere decir que la muerte es exterior a la vida y no pertenece a ella, pues cuando hay vida no hay muerte y en cuanto se presenta la muerte ya no hay vida. Arrojar la muerte al exterior no es sino eludirla, lo que no deja de ser sino consecuencia de una actitud tanatófuga - y tanatófoba - frente a ella. Entre muerte y vida se establece entonces una separación radical, de modo que la muerte no es actuante en la vida ni modeladora de su carácter. La muerte es justo el límite de la existencia, un límite exterior, que ya no forma parte de aquello que delimita, y por tanto no puede ser — no es — una experiencia del existente. En palabras de Wittgenstein, que sería otro egregio representante de esta comprensión epicúrea de la muerte como límite y exterioridad, «la muerte no es un acontecimiento (Ereignis) de la vida. La muerte no se vive $(\text { erlebt) }\rangle^{43}$. Desde esta posición, resulta patente que no hay vivencia de la muerte por parte del existente, de manera que entonces, a falta de experiencia directa, sólo nos queda como experiencia de la muerte la del otro, y «sólo mediante ella establecemos nuestra relación con nosotros mismos

41 Epicuro, Epistula ad Menoeceum (125), 5-8, Opere, G. Arrighetti (ed.), Torino: Einaudi, 1973, p. 109.

42 Montaigne, M. de, Les Essais op. cit., L. I, ch. xx, p. 95.

43 Wittgenstein, L., Tractatus lógico-philosophicus (1921), 6.4311, Schriften 1, Frankfurt a. M., Suhrkamp, 1980, p. 81; cfr. Schumacher, B. N., Der Tod in der Philosophie der Gegenwart op. cit., p. 249. 
como mortales» ${ }^{44}$.

\section{LiterATURA Y FILOSOFÍA DE LA INTERIORIZACIÓN DE LA MUERTE}

En efecto, la muerte es punto final del decurso de la vida, y si sólo fuese esto estaría al margen del propio vivir. Pero no es sólo eso. Frente a esa filosofía de la exteriorización, también hay una filosofía de la interiorización de la muerte. Realmente, la muerte no es un simple elemento exterior de la vida, sino un elemento interior y constitutivo de la existencia, algo que forma parte de ella. La muerte está incorporada al existir. La vida misma alberga la muerte. Así, ha considerado generalmente la filosofía a la muerte, bajo la condición de incorporarla a la existencia para entenderla como algo interior y actuante en el propio vivir. Pero no sólo la filosofía, hay además una literatura de la interiorización de la muerte. También la literatura ha comprendido que la muerte forma parte esencial de la vida y que no se puede comprender la vida en su radicalidad sin la muerte como elemento configurador de su estructura. La muerte está ya en la vida, es, en cierto modo, la propia vida. Por eso pudo escribir O. Paz que «nadie se muere de la muerte, todos morimos de la vida», porque la vida contiene la muerte, por lo que «los vivos no están vivos» ${ }^{45}$. El poeta Alfonso Reyes, a fuerza de internar la muerte en la vida, llega al extremo no ya de hacerla formar parte de la existencia, sino incluso de convertir la vida en muerte: «Eras la muerte y te llamé la vida» ${ }^{46}$. La muerte por tanto no es un mero límite separador, algo ajeno y exterior a la contextura vital, y en consecuencia ignoto y misterioso. Este sería un aspecto del misterio de la muerte, su áspera extranjería, su indiferente ajenidad. Pero contra esta exteriorización de la muerte, Quevedo ya nos amonestó: «La muerte no la conocéis, y sois vosotros mismos vuestra muerte, tiene la cara de cada uno de vosotros y todos sois muertes de vosotros mismos» ${ }^{47}$. Lejos de ser sólo algo al margen, extraño y exterior, la muerte según Quevedo nos acompaña radicalmente pues «lo que llamáis morir es acabar de morir y lo que llamáis vivir

44 Dastur, F., La mort. Essai sur la finitude, Paris: PUF, 2007, p. 25.

45 Paz, O., «¿No hay salida?» (1952), La estación violenta, Lo mejor de O. Paz: el fuego de cada día, Barcelona: Seix Barral, 1989, p. 77.

46 Reyes, A., «Visitación» (1951), Jornada en sonetos, Obras completas, Constancia poética, t. X, México: FCE, 1996, p. 458.

47 Quevedo, F. de, «El sueño de la muerte», Sueños (1627), Obras completas. Obras en prosa, t. I, F. Buendía (ed.), Madrid: Aguilar, 1979, p. 199. 
es morir viviendo» ${ }^{48}$. Tan interior es la muerte a la vida que Quevedo, algo después de Sueños, la identifica con ella: «Empieza el hombre a nacer y a morir; por esto, cuando muere acaba a un tiempo de vivir y de morir $\rangle^{49}$. Cuna y sepultura, nacimiento y muerte, principio y fin, aparentemente tan distintos, tan distantes, tan extraños entre sí, pero en realidad tan cercanos y hermanados que Quevedo le recuerda al ser humano que «a la par empiezas a nacer y a morir», $\mathrm{y}$ «que naciste para morir y que vives muriendo» ${ }^{50}$. Contra la cesura radical entre vida y muerte, vivir es morir. Contra la ajenidad, la familiaridad y el entrañamiento de la muerte en la vida.

Apartándose de la tanatófuga modernidad, esta comprensión integradora - tanto en la versión existencialista como en la vitalista- ha arraigado especialmente en el pensamiento del s. XX debido a que «ha descubierto la presencia inevitable de la muerte en el seno de la vida humana ${ }^{51}$, descubrimiento que ha justificado la trascendencia filosófica del concepto de muerte. El pensamiento de Ortega, como ya sabemos, es un buen ejemplo de esta posición cuando dice «reconocer en la muerte el atributo más esencial de la vida» y añade, en consecuencia, que «no puede definirse la vida sin la muerte» porque «desde el primer momento, va la vida lanzada a su consumación: tanto vale decir que se vive como que se desvive. El fenómeno del morir se va produciendo desde la concepción» ${ }^{52}$. Por esto mismo, no se puede admitir de entrada y sin matizar la afirmación de Cerezo según la cual «la muerte no cuenta filosóficamente en su planteamiento $\aleph^{53}$. Cerezo introduce esta tesis para diferenciar la posición orteguiana de la unamuniana - e incluso podría haber valido para distinguirla en general de la perspectiva existencialista. Ortega practicaría entonces una reducción secularizadora de la muerte y de la voluntad de no morir al comprenderlas como hechos puramente naturales, en principio sin calado filosófico en su sistema, mientras que Unamuno las entiende desde un horizonte trascen-

48 Ibíd., p. 199. En otra edición de este mismo texto se añade que «lo que llamáis nacer es empezar a morir», Quevedo, Sueños, Madrid: Espasa-Calpe, 1978, p. 114.

49 Quevedo, F. de, La cuna y la sepultura (1634), OC II op. cit.,p. 1325.

50 Ibíd., pp. 1328, 1330. Por tanto, añade, «antes empiezas a morir que sepas qué cosa es vida» (p. 1329).

51 Laín Entralgo, op. cit., p. 23.

52 Ortega, «Notas del vago estío» op. cit.,p. 547.

53 Cerezo, P., «Tres paradigmas del pensamiento español contemporáneo: trágico (Unamuno), reflexivo (Ortega) y especulativo (Zubiri)», Isegoría 19 (1998), 97-136, p. 104. 
dente y religioso que es el que da forma a su filosofía. La consideración de Cerezo entonces es acertada en el sentido de que, en efecto, la muerte y la voluntad de no morir, como meros hechos, no tienen relevancia filosófica en la propuesta orteguiana. Pero aunque el pensamiento de Ortega no deja de concebir la muerte como simple hecho, su filosofía sobre la muerte no se limita a esa positivista comprensión. En efecto, la muerte tiene peso en el pensamiento orteguiano gracias a una determinada actitud vital que es naturalmente la que por un lado le garantiza su adscripción a aquella filosofía de la interiorización de la muerte, y por otro le permite incorporar la muerte a la vida. Esta precisa actitud es la que tiene verdaderamente significado filosófico y la que le presta relevancia filosófica a la muerte en el pensar orteguiano. Lógicamente, la disposición ante la vida y la postura ante la muerte están unidas, van juntas, de modo que de aquella cierta actitud vital orteguiana se desprenderá una concreta actitud ante la muerte. Dichas actitudes son tan inseparables, tan indistinguibles, que en el fondo son una y se resume en arrostrar la muerte sin miedo. Esta actitud es la que caracterizará la peculiar comprensión interior vitalista de la muerte practicada por Ortega frente a la existencialista, y es en definitiva la que permite decir a Cerezo, sin entrar en contradicción con su anterior enunciado, que «Ortega ha visto bien que la muerte, como el revés de la vida, muestra mejor que ningún otro signo la altura y profundidad del proyecto vital» ${ }^{54}$.

Esta singular actitud ante la vida y la muerte es la que legitima el modo propiamente orteguiano de integrar la muerte en la vida a diferencia del unamuniano y heideggeriano y por este motivo será nuestro próximo objeto de interés. Estos diversos modos de incorporar la muerte en la existencia dependen de dispares actitudes fundamentales ante la vida y representan a su vez diferentes estilos filosóficos. El modo existencialista de integrar la muerte, supeditado a la actitud existencialista ante la vida, entiende la existencia en relación con la muerte, que es la que le daría finalmente sentido, y el vitalista, dependiente de la actitud vitalista ante la existencia, afirma la vida como valiosa por sí y concibe la muerte como final adecuado de una vida plena e inspirada que la enfrenta sin miedo. El primero es propio de lo que podemos denominar 'filosofía de la muerte', como p. e. la de Unamuno o Heidegger, y el segundo pertenece a la 'filosofía de la vida', como es la de Ortega, pero también p. e. la de Nietzsche

54 Cerezo, P., La voluntad de aventura op. cit., p. 155n. 
o Simmel. El 4 de enero de 1937 escribía Ortega que la vida y la filosofía de Unamuno - que había muerto cuatro días antes - eran una «meditatio mortis», o sea, una 'filosofía de la muerte', y añadía que «hoy triunfa en todas partes esta inspiración, pero es obligado decir que Unamuno fue su precurson», pues incluso en los años en que los europeos se olvidaron de que tenían que morir y «andaban más divertidos con las cosas de dentro de la vida, este gran celtíbero hizo de la muerte su amada $\aleph^{55}$. Es indudable que con esa inspiración tanatófila triunfante Ortega se refiere al existencialismo, especialmente al heideggeriano, aunque también al horror de la Guerra Civil española, cuyo arrebato necrófilo pronto se extendería trágicamente por toda Europa. El sello del existencialismo como filosofía de la muerte se halla claramente revelado en el Sein zum Tode de Heidegger, es decir, en la concepción de la existencia como angustia, como algo que es relativamente o respecto de la muerte y por tanto de la nada. Por eso concibe la muerte como «la posibilidad más propia (eigenste Möglichkeeit)» del Dasein $^{56}$. Pero Ortega, como ilustre representante de la filosofía de la vida, tiene meridiana conciencia de que su pensamiento está en las antípodas de ese existencialismo: «Mi doctrina respecto a la muerte es estrictamente inversa de la existencialista $\rangle^{57}$. Aclarar en qué consiste esta inversión nos va a permitir penetrar en la esencia del concepto orteguiano de la muerte, y ello porque aunque esta inversión se produce a partir de Sein und Zeit y por tanto se refiere a lo que podemos considerar el 'segundo Ortega ${ }^{58}$, la

55 Ortega, «En la muerte de Unamuno» op. cit., p. 409.

56 Heidegger, M., Sein und Zeit, op. cit., \50, p. 333.

57 Ortega, El hombre y la gente (1949-1950) (Notas), op. cit.,p. 491.

58 No podemos extendernos sobre el problema de las distintas etapas del pensamiento orteguiano (cf. Ferrater Mora, J., Ortega y Gasset. Etapas de una filosofía, Barcelona: SeixBarral, 1973, pp. 19ss; Silver, Ph., Fenomenología y razón vital. Génesis de Meditaciones del Quijote' de Ortega y Gasset, Madrid: Alianza, 1978, pp. 17-30; Cerezo, P., La voluntad de aventura op. cit., pp. 15ss; Villacañas, J. L., «Introducción. La primera singladura de Ortega» en Meditaciones del Quijote, Madrid: Biblioteca Nueva, 2004, pp. 12-20, 51-58). Defendemos la tesis de un Ortega en formación — armado ya sin duda de un germen personal— hasta los años 1911/1912, y a partir de entonces se inicia la 'filosofía personal' de Ortega dividida en dos etapas fundamentales. El 'primer Ortega' tiene su texto fundacional en Meditaciones del Quijote de 1914 y presenta luego, a principios de los veinte, una inflexión de corte algo vitalista expuesta principalmente en El tema de nuestro tiempo de 1923. La escisión que da inicio al 'segundo Ortega', marcado esencialmente por una radicalización fenomenológico/biográfica de la idea de vida humana, se produce a finales de la década de los veinte con ¿Qué es filosofía?, y él mismo la hace explícita al final del prólogo que 
posición filosófica adoptada responde perfectamente al espíritu personal de su pensamiento y a su actitud ante la vida y la muerte expresada ya a finales de la década de los diez y especialmente en los veinte.

Es evidente que esclarecer esa inversión implica profundizar en estos dos modos de filosofía de la interiorización de la muerte, y los dos estilos filosóficos que entrañan, los cuales representan a su vez dos modos de entender la finitud sobre una base común, de cuya existencia da fe el propio Ortega. De la mano de Heidegger, indagando en el sentido profundo de las palabras, Ortega escribe que «Endlicbkeit (finitud) no será meramente una limitación aneja al hombre, pero que no es el hombre mismo, sino que será todo lo contrario, Seiender Ende o Sein als Ende (ser como fin), con lo cual este —el Ende (fin) — no queda fuera del hombre como los límites habituales, sino que viene a constituir su esencia misma. El hombre, en efecto, desde que nace está ya muriendo, como dijo Calderón; por tanto, empieza por acabar y vive de su muertes ${ }^{59}$. La existencia desde luego no es in-finita, tiene fin, pero lo primordial es que dicho fin no es exterior sino interior a la existencia misma. El hecho de que tanto la filosofía de Ortega como la de Heidegger asuman la interiorización de la muerte en la vida significa que son filosofías de la fin-itud pues suponen la integración del fin en la propia existencia y la comprensión del ser humano como ser que desde que nace ya muere. Ahora bien, cada una de ellas entiende de forma distinta la manera de incorporar el fin a la vida y, en este sentido, son dos filosofías diversas de la finitud, dos modos de comprender la finitud. Lo que pretendemos ahora es descubrir el modo orteguiano de hacerlo, lo que implica aclarar la actitud — vitalista — ante la vida y la muerte de la que depende la puesta en práctica de esa interiorización de la muerte en la existencia.

redactó para sus primeras Obras completas en 1932, donde advierte que «empieza, pues, nueva tarea. ¡Al mar otra vez, navecilla! ¡Comienza lo que Platón llama 'la segunda navegación'!», Ortega, Prólogo a una edición de sus 'Obras' (1932), OC V op. cit., p. 99.

59 Ortega, «En torno al Coloquio de Darmstadt, 1951», OC VI op. cit., p. 807. Lo que dice exactamente Calderón en una décima es que «quien está desde que nace / en los brazos de la muerte», Calderón de la Barca, P., «jOh, tú que estás sepultado!» (1625-1656), Poesía, Madrid, Cátedra, 2018, p. 357; y también en otro lugar escribe: «Pues, si a morir viviendo el hombre nace», Calderón, P., « $\mathrm{Oh}$, rompa ya el silencio el dolor mío!. Elegía en la muerte del Señor Infante Don Carlos» (1632), Poesía, op. cit., p. 231. 


\section{LA MUERTE COMO SER PARA LA VIDA}

Como representante de la filosofía de la interiorización de la muerte, Ortega integra la muerte en la existencia, pero lo hace, frente a Heidegger, en virtud de una actitud vitalista ante la vida y la muerte. Lo que nos queda ahora por esclarecer es cómo lo hace, qué es lo que distingue su forma de internar la muerte en la existencia de la heideggeriana. El ser humano muere, tiene que morir. Pues bien, con su Sein zum Tode, Heidegger interioriza el tener que morir haciéndolo formar parte de la vida como lo esencial de ella y convirtiendo entonces la muerte en sustancia de su filosofía. Heidegger ha internalizado el tener que morir por principio, de entrada, de manera que la muerte — y la nada en que desemboca — viene a ser como un a priori de sentido de la existencia. Esto es lo que quiere decir realmente el Sein zum Tode, ser para la nada, pues realmente lo que hace es enfrentarnos a la nada. Por este motivo la angustia es el pathos primordial del existencialismo heideggeriano. De aquí se desprende que la incorporación esencial de la muerte practicada por Heidegger que representa no significa otra cosa que afirmar con radicalidad la finitud humana, una finitud centrada en la angustia. Ortega se aparta de este apriorismo heideggeriano al entender la muerte como un hecho para luego, a posteriori, integrarla en la vida, pero no la interna de entrada. Esa incorporación de la muerte en la vida realizada por Ortega no es a priori sino que depende de una actitud vital y de un determinado modo de vida. Sólo así, mediante la internación de la muerte que consigue esa precisa actitud existencial, sólo así, logra darle sentido a la vida -y a la propia muerte. Ya no es el serpara la muerte el sentido del existir sino una cierta forma de vivir que permite la integración de la muerte en la vida, es decir, el serpara la vida. «En la metafísica de la vida humana de Ortega no cabe el ser para la muerte de Heidegger», escribe Cerezo, y añade que «la muerte cuenta, pero no como límite y estación final, sino como componente de la interna trasmutación de la vida. No es sólo muerte aceptada de antemano, sino integrada y consumada en la obra de vivir» ${ }^{60}$.

Interiorizar la muerte en la vida quiere decir en Ortega aprovecharla,

60 Cerezo, P., «Las dimensiones de la vida humana en Ortega y Gasset», en Las dimensiones de la vida humana. Ortega, Zubiri, Marías y Laín Entralgo, J. San Martín y T. Domingo (eds.), Madrid: Biblioteca Nueva/Fundación José Ortega y Gasset, 2010, 19-52, p. 36. 
emplearla (a posteriori) en la vida para de esa forma darle sentido al propio vivir. La versión vitalista de la incorporación realizada por Ortega significa que puesto que la muerte es un factor o ingrediente de la vida, «lo mismo que debemos usar deliberadamente de ésta, debiéramos también usar de la muerte, aprovecharla, emplearla (...) Parece de mayor dignidad humana aprovechar el hecho y la fuerza que es la muerte, usando de ella bajo el regimiento de la voluntad $»^{61}$. Esta última afirmación, además de insistir en la pertenencia de Ortega a esta filosofía de la interiorización, anuncia ya la actitud clave que lo diferencia de Heidegger: el ser humano no es para morir, el sentido de su angustiada existencia no es estar ahí para la muerte, para la nada, sino que la muerte es ahora empleada por la vida. Por eso la muerte en Ortega deja de ser el elemento sustancial relativamente al cual es la vida, el que da sentido a la vida, para subordinarse a la propia vida, la cual, convertida en sentido y meta de ella misma, se incorpora la muerte — la aprovecha - para ser más vida, para plenificarse de la manera que ahora expondremos. La muerte entonces lógicamente ya no es un mero hecho mundano externo, ajeno a nosotros, a nuestro vivir, ya no es el final no perteneciente a la vida, sino que es integrada mediante la voluntad en la vida y, de este modo, usada. Sigue siendo la muerte un hecho, qué duda cabe, pero, afirma Cerezo, un hecho «que cabe asumirlo e internalizarlo en la misma obra de la vida» ${ }^{62}$, o sea, emplearlo. Lejos de que la existencia sea un 'ser para la muerte', aquí la muerte es (usada) para la vida, es un 'ser para la vida'. Evidentemente, este uso de la muerte se corresponde con lo que — siguiendo a Ortega — habíamos denominado sentido estético del morir $\mathrm{o}$ arte del morir y que no quiere decir otra cosa que aprovecharla, cincelarla o modelarla creativamente como si fuera materia para un arte, para el arte en suma de vivir. Entonces el ser humano puede ser entendido esencialmente como artista de la muerte pues la convierte en objeto estético al servicio de una vida auténtica, intensa. En definitiva, este 'arte del morir' significa vivir de tal modo que la muerte se aproveche, sea creativa, tenga sentido y dé sentido a la existencia: «La muerte como creación», titula Ortega ${ }^{63}$. La actitud vitalista orteguiana en el fondo es una ética de la muerte creativa.

61 Ortega, «Notas del vago estío» op. cit., p. 548.

62 Cerezo, P., «La ética de la alegría creadora», Revista de estudios orteguianos 18 (2009), 129-

170 , p. 167.

63 Ortega, «Notas del vago estío» op. cit., p. 546. 
Por tanto, en Ortega la pregunta por la interiorización vital de la muerte equivale a la pregunta por cómo usa creativamente el ser humano la muerte para esculpir una vida plena.

Dado que la muerte en Ortega es 'ser para la vida', responder a esas preguntas sobre el fenómeno mortal supone entender exactamente el alcance de esta actitud vitalista, y para ello es necesario reparar en que está dirigida por la comprensión fundamental de la vida humana como proyecto defendida por Ortega. La vida humana consiste en misión, tiene esencialmente un objetivo o ideal por conseguir, de manera que «para vivir con plenitud necesitamos un algo encantador y perfecto que llene exactamente el hueco de nuestro corazón ${ }^{64}$. La autenticidad o plenitud de la vida humana por tanto no reside meramente en el hecho de tener una meta, sino más bien en que toda nuestra vida esté volcada en su realización hasta las últimas consecuencias, esto es, hasta el extremo de dar su vida y morir en el empeño. Esto implica que esa meta debe ser algo ideal según Ortega, esto es, algo lo suficientemente atractivo como para llegar a entregarle la propia vida: «El hombre está dispuesto a derramar su vida precisamente por algo que sea capaz de llenarla. Esto es lo que llamamos el ideal $\rangle^{65}$. Esta es la actitud y el modo vital con el que Ortega incorpora la muerte en la vida. Frente al espíritu burgués industrial y calculador, utilitarista y negociante, que predomina en el s. XIX, esa actitud vitalista es denominada por Ortega «espíritu guerrero» o también heroico, y consiste en aquel «estado de ánimo habitual que no encuentra en el riesgo de una empresa motivo suficiente para evitarla» ${ }^{66}$. En la actitud vitalista orteguiana el criterio que decide el valor de autenticidad y plenitud de la vida es el hecho de jugarse la vida por lograr la meta propuesta: «El valor supremo de la vida está en perderla a tiempo y con gracia», ya que, añade, «la vida que no se pone a carta ninguna y meramente se arrastra y prolonga en el vacío de sí misma, ¿qué puede valer? $\rangle^{67}$. Sólo vale la vida que se pone a una carta incluso al precio de morir por ello. Sólo ella es una vida plena e intensa. Sólo ella interna la muerte con sentido en el vivir. Ahora bien, aunque no haya para Ortega una meta material universal para todos los sujetos, sí hay un fin

64 Ortega, Introducción a un 'Don Juan' (1921), OC VI op. cit., p. 198.

65 Ibid.

66 Ortega, «Notas del vago estío» op. cit.,p. 545.

67 Ibid., p. 547. 
último a nivel formal y con valor universal al que dirigir adecuadamente la existencia: ser uno mismo. En efecto, de entre todos los proyectos posibles y concretos de vida hay uno que formalmente afecta a todos, que es el llegar a ser lo que se es, realizar (en acto) el sí mismo particular que cada uno está llamado a ser (en potencia). Desde el inicio de su obra hasta el final, el pensamiento de Ortega está modelado y dirigido explícitamente por el imperativo moral/existencial de la coincidencia consigo mismo expuesto por Píndaro: «Llega a ser el que eres» ${ }^{68}$. Cada persona según Ortega está vocada/destinada a ser algo peculiar y exclusivo, que sería su perfección, su mejor poder ser, su ideal, pues «cada cosa al nacer trae su intransferible ideal» ${ }^{69}$. El proyecto de todo ser humano, su vocación, es llegar a ser él mismo, es decir, perfecto, pues, confiesa Ortega, «yo creo ver todo hombre que ante mí pasa como inscrito en una silueta moral de sí mismo: ella precisa lo que su carácter individual sería en perfección ${ }^{70}$. Autenticidad y perfección van de la mano en la filosofía orteguiana. De aquí se desprende que si pretendemos ser auténticos la existencia no puede consistir en otra cosa que en «la inexorable forzosidad de realizar el proyecto de existencia que cada cual es», de manera que es un drama, una lucha «por conseguir ser de hecho el que somos en proyecto» ${ }^{71}$. El sí mismo es sólo un proyecto, no lo somos sin más, es una vocación a la que estamos destinados y que tenemos que llegar a ser, pero precisamente por ello podemos también no serlo y traicionar nuestro auténtico ser.

\section{HumANiZACión DE LA MUERTE}

En el pensamiento de Ortega, vida plena, intensa, auténtica, perfecta y heroica son una misma cosa consistente en una vida puesta a la carta de ser uno mismo incluso al precio de morir, pues en efecto hay ocasiones en que un individuo, "para ser fiel a sí mismo, necesita volcarse íntegro en la muerte ${ }^{72}$. Aprestarse a morir si es preciso por ser fiel a sí mismo es lo propio de la intensidad vital, de modo que «en todas las épocas de vida intensa, la gente está dispuesta a morir por algo, pues «el afán de morir es

68 Ortega, «Estética en el tranvía» (1916), El Espectador I, p. 181; El hombre y la gente (19491950) op. cit., p. 148.

69 Ortega, «Estética en el tranvía» op. cit., p. 180.

70 Ibid., p. 181.

71 Ortega, Pidiendo un Goethe desde dentro (1932), OC VI op. cit., pp. 124s.

72 Ortega, «Muerte y resurrección» (1917), El Espectador II, op. cit.,p. 287. 
el síntoma más evidente de la energía vital ${ }^{73}$. Cuando es el desenlace de una existencia comprometida con la autorrealización, la muerte deviene en la filosofía de Ortega el síntoma - y criterio— de plenitud vital y autenticidad. Para Ortega el valor de una vida, su plenitud y autenticidad, depende de su vitalidad, de su intensidad, es decir, de su capacidad de entregarse absolutamente a una causa, al precio que sea: «El hombre no puede vivir plenamente si no hay algo capaz de llenar su espíritu hasta el punto de desear morir por ello» ${ }^{74}$. Vale la vida que en el cumplimiento de su misión se arriesga incluso a morir. La muerte por tanto es integrada en la existencia por Ortega como criterio de vitalidad, como índice de la intensidad de la vida: «Lo que no nos incita a morir no nos excita a vivir» ${ }^{75}$. De ahí se desprende además que entonces la muerte es el patrón de medida de aquello que más vale en nuestra vida, aquello por lo que estamos dispuestos incluso a jugarnos la vida: «El aparato que mejor registra la jerarquía de nuestros entusiasmos vitales es precisamente la muerte. Será lo más importante en nuestra vida aquello por que seamos capaces de morir» ${ }^{76}$.

Ahora bien, ser uno mismo, evitar el natural, poderoso y casi siempre cómodo impulso de adaptarse a las circunstancias, es algo heroico. Ya en 1914 Ortega había destacado que «este querer él ser él mismo es la heroicidad», o sea, que entonces «ser héroe consiste en ser uno, uno mismo»" Y más heroico aún si es al precio de perder la vida. Ciertamente, asegura Ortega, «ese esfuerzo, en que el hombre se toma a sí mismo en peso todo entero y se apresta a lanzar su existencia allende la muerte es lo que de un hombre hace un héroe» ${ }^{78}$. Jugarse la vida física por ser uno mismo es la esencia de la heroicidad, de modo que lo propio de lo heroico es una «voluntaria anticipación de la muerte ${ }^{79}$. La vida heroica es vida comprometida, entregada y altruista, justo lo contrario de la vida egoísta que sólo persigue salvar su propia existencia material. Respecto del héroe, Cerezo confirma que «el empeño de su vida es aquello que lo lleva a la muerte», y por ello «la voluntad de ser del héroe, a diferencia del mero subsistir biológico, resulta

73 Ortega, «Para un museo romántico» op. cit., p. 629.

74 Ortega, «Ideas sobre Pío Baroja» (1916), El Espectador I, op. cit.,p. 228.

75 Ibid.

76 Ortega, «El ocaso de las revoluciones» (1923), OC III op. cit., p. 630.

77 Ortega, Meditaciones del Quijote op. cit.,p. 816.

78 Ortega, Introducción a un 'Don Juan' op. cit.,p. 198.

79 Ortega, «Notas del vago estío» op. cit.,p. 548. 
indiscernible de su propia voluntad de morir $\rangle^{80}$. Por tanto, subraya Lasaga, si lo que nos manda la vida auténtica es «llegar a ser el que se tiene que ser», entonces «sólo cumple el mandato pindárico quien expone su vida a una carta - la de la propia vocación» ${ }^{81}$. Desde luego no lo cumple el ser humano masificado, el ser humano ordinario, que, a diferencia del héroe, «da una importancia enorme a eso de perder la vida ${ }^{82}$, razón por la cual además no puede entender que alguien, el héroe, el ser humano auténtico, pueda poner en peligro su vida material por querer ser él mismo. Ese tipo de humanidad es heredero del sujeto burgués calculador y utilitarista del s. XIX para la cual, de acuerdo con la ética tanatófuga moderna, «todo era preferible a morir» y «quiere a toda costa vivin»; ahora bien, no hay otra técnica para retrasar la muerte y alargar la existencia que «reducirla a su mínima expresión (...) vita minima (...) la vida se prolonga en la medida que no se usa. Se obtiene su extensión a costa de su intensidad $\rangle^{83}$. Cuando el valor principal de una vida es conservarse a sí misma al precio que sea, cuando un individuo mantiene su vida a costa de ser infiel a él mismo y traicionarse o falsificarse, se trata de una vida de baja intensidad, exenta de plenitud, inauténtica.

Entender la muerte como consecuencia de una libre y arriesgada vida gobernada por el propio sujeto y no por la cómoda adaptación a las circunstancias con la meta innegociable de ser uno mismo supone hacerse dueño de la muerte, apropiársela. Una vida en libertad, poseída por uno mismo, implica poner también la muerte bajo la dirección de la libertad, usarla y esto es —en definitiva - cincelarla. El sentido estético del vivir - y el morir - desemboca en el gobierno de la muerte. Interiorizar la muerte, incluirla en la vida como resultado de una vida heroica dirigida por uno mismo con vistas a la autorrealización es todo un arte, el arte del morir que reclamaba Ortega, la cultura de la muerte que pedía frente a la vergonzosa huida moderna y burguesa ante la muerte. Este es el uso artístico de la muerte al que aspiraba Ortega. El sentido estético de la muerte se consuma en su incorporación a la vida, cuando la muerte es el desenlace

80 Cerezo, P., La voluntad de aventura op. cit.,p. 155.

81 Lasaga, J., Figuras de la vida buena (Ensayo sobre las ideas morales de Ortega), Madrid: Enigma/ Fundación José Ortega y Gasset, 2006, p. 115.

82 Ortega, Principios de metafísica según la razón vital (Curso de 1933-1934), OC IX op. cit., p. 107.

83 Ortega, «Notas del vago estío» op. cit., p. 547. 
de una vida heroica, una vida cincelada que se la juega a una carta: «Seamos poetas de la existencia que saben hallar a su vida la rima exacta en una muerte inspirada» ${ }^{84}$. Sólo entonces tiene la muerte sentido creativo y humano. Integrar la muerte en la vida mediante la libertad, estetizarla, es humanizarla, evitar que sea reducida a simple muerte química o material, o sea, a hecho conclusivo de la existencia, al margen del vivir humano como tal: «La muerte química es infrahumana. La inmortalidad es sobrehumana. La humanización de la muerte sólo puede consistir en usar de ella con libertad, con generosidad y con gracia» ${ }^{85}$. Usar la muerte es interiorizarla en la existencia modelándola, convirtiéndola en consecuencia de una vida vivida humanamente, una vida cuyo protagonista es el dueño que la dirige libremente hacia la verificación de sí mismo asumiendo, si es necesario, la posibilidad de morir. La muerte entonces, sin dejar de ser un hecho y debido a la vida intensa, es internada a posteriori en la existencia, a diferencia de Heidegger, donde la muerte no es básicamente un hecho sino un hecho convertido en a priori de sentido, un elemento trascendental. En Ortega lo único trascendental sería la propia vida pues sólo cuando es auténtica le presta sentido a la muerte, que equivale entonces a una recompensa creativa a dicha vida heroica.

Contra el serpara la muerte y la nada heideggeriano, la vida aquí ya no es referida a la muerte, sino que es la muerte la que, cuando es prueba de vida plena, se remite a la vida, que queda establecida por Ortega, algo de sobra conocido, como valor fundamental. La vida ya no es un angustiado serpara la muerte, no es para morir, sino que más bien el sentido de la vida es la entusiasta ejecución de un proyecto, una misión, concretamente el quehacer de ser uno mismo, la vocación. «La vida como angustia, señor Heidegger, ¡muy bien!, pero además la vida como empresa», reclama Ortega ${ }^{86}$. La vida humana no es para la muerte y la nada sino para la plenitud de sí misma, para la autorrealización. De acuerdo con esto, Cerezo sostiene que «lo propio del mortal para Ortega no es tener que morir, verdad sencilla y plana, sino tener que hacer su vida, y ésta, paradójicamente, no está orientada a la muerte, a diferencia del heideggeriano Sein zum Tode, sino a su vocación

84 Ibid., p. 549.

85 Ibid.

86 Ortega, La razón histórica (Curso de 1940), OC IX op. cit., p. 541. 
y, por tanto, a la plenitud d su vida $»^{87}$. Por tanto, «a diferencia de Heidegger, el hombre no es un ser para la muerte, sino para el cumplimiento de su proyecto de ser humano» ${ }^{88}$. Pero no sólo la vida no es 'ser para la muerte'; más bien, la muerte es ser para la vida en tanto su sentido no es otro que ser culminación de una vida heroica. El sentido de la muerte es entonces ser criterio de vida auténtica, de vita maxima. El 'ser para la vida' de la muerte es estar remitida a la vida como su criterio o prueba de valor, algo que sólo ocurre cuando es el resultado de una vida intensa. Esto es humanizar la muerte. Esto quiere decir que la interiorización (humanización) de la muerte en la vida es realizada por Ortega desde la perspectiva de la primacía de esta última categoría. No se trata por tanto de buscar la muerte sin más, lo que supondría reasumir el 'ser para la muerte', pues, en palabras de Cerezo, «exponerse a la muerte no es de suyo ningún síntoma de virilidad (virtus) ética, si no va acompañado de una profunda afirmación de un sentido en la vida» ${ }^{89}$. Ese sentido es aquello por lo que entrega la vida y se muere. Lo que se pretende es exponer la vida por algo. Esto es lo importante, no morir en sí mismo, sino morir humanamente, o sea, como efecto de una vida expuesta y dedicada a la misión de ser sí mismo. Se trata por tanto de vivir y el criterio para decidir el valor de este 'ser para la vida' es si estamos dispuestos a morir por vivir intensamente, o sea, por ser nosotros mismos. Este compromiso absoluto es la prueba de la plenitud vital. Cuando esto sucede la muerte es creativa, humana, pues consiste en fruto, síntoma y salvación de una vida heroica que, en este sentido, se justifica y renace, no se pierde, no se desvanece totalmente. Ortega asegura que «siempre en la voluntad de morir se busca una resurrección»» $»^{90}$ Ortega interioriza la muerte de modo vitalista, esto es, dándole poder creativo, ya que cuando la muerte es efecto de una vida heroica es, a su vez, síntoma de que esa vida es más vida, es una vida que, aunque muere material o temporalmente, resucita en tanto que es afirmada, plenificada. Esta muerte como creación -humanizada- sólo puede ser alegre, ya que es la secuela de una vida que se legitima y se salva, lo cual sólo puede producirnos regocijo, satisfacción: «La muerte regocijada es el síntoma de toda cultura vivaz y

87 Cerezo, P., «La ética de la alegría creadora» op. cit., p. 167.

88 Cerezo, P., «Las dimensiones de la vida humana en Ortega y Gasset» op. cit., p. 50.

89 Cerezo, P., «La ética de la alegría creadora» op. cit., p. 143.

90 Ortega, «Muerte y resurrección» op. cit.,p. 287. 
completa, donde las ideas tienen eficacia para arrebatar los corazones ${ }^{91}$.

\section{CONCLUSIÓN: INCORPORAR \\ VITALMENTE LA MUERTE EN LA VIDA}

La comprensión orteguiana de la muerte, verdadero núcleo de encuentro de las grandes corrientes de pensamiento de su filosofía, sortea tanto el aburguesamiento moderno ante la muerte como la angustiada interpretación de Heidegger. Lo que salva Ortega no es el simple vivir, el puro prolongarse de la existencia, sino la vida en su esencia, la vida comprometida, entregada a la carta de ser uno mismo. Pero tampoco interna la muerte buscándola, lo que convertiría la filosofía de Ortega en otra filosofía existencialista de la angustia. Interioriza la muerte plenificando la vida, viviéndola con intensidad. Esta es la diferencia fundamental, que Ortega, como filósofo de la vida, incorpora la muerte vitalmente, desde la vida y no por ella misma, a priori, como hace Heidegger, filósofo de la muerte. Lo esencial de la vida no es ni tener que morir, que es un hecho, ni el hambre de inmortalidad que ya presupone ese hecho, sino plenificarse, ser más vida. En Heidegger - y en Unamuno- a la postre pesa más la muerte, el tener que morir, y en Ortega el modo de vivir, y desde él, cuando es vida en plenitud, como la muerte es sólo un hecho, se la incorpora. Si es un vivir plano, entonces la muerte no es integrada en la vida y queda reducida a hecho final del vivir, un hecho que se quiere aplazar el mayor tiempo posible. Heidegger ha esencializado ese hecho, la muerte, y así, convirtiéndola como tal hecho en lo primordial, la ha integrado en la vida como su horizonte a prio$r i$ respecto del cual tiene sentido. La muerte es un hecho, pero en sí misma no es la nota clave de la existencia. El hecho de la muerte importa - y esto es lo que hace Ortega- cuando es interiorizado como consecuencia de una vida auténtica, como 'rima precisa de una vida estetizada'. Ortega interna la muerte sin trasformarla en lo esencial; la muerte forma parte de la vida pero ésta sigue siendo lo sustancial. Es más, puesto que la muerte sólo pertenece verdaderamente a la vida cuando es el producto último de una vida heroica, el fruto de una vida capaz de jugársela a una carta, puede afirmarse que Ortega interna la muerte para afirmar la vida.

91 Ortega, «Ideas sobre Pío Baroja» op. cit., p. 228. 
REFERENCIAS BIBLIOGRÁFICAS:

Las obras de Ortega y Gasset han sido citadas siempre que se ha podido a partir de la edición de las obras completas de la Fundación Ortega y Gasser y Taurus en Madrid durante los años 2004-2010. Así:

Ortega y Gasset, J., 1937: «En la muerte de Unamuno», en OC V.

Ortega y Gasset, J., «Asamblea para el progreso de las ciencias» (1908), OC I.

Ortega y Gasset, J., «Azorín: primores de lo vulgar» (1917), El Espectador II, OC I,

Ortega y Gasset, J., «Corazón y cabeza» (1927), OC VI.

Ortega y Gasset, J., «El hombre español», Sobre una nueva interpretación de la historia universal, OC IX.

Ortega y Gasset, J., «En torno al Coloquio de Darmstadt, 1951» (1952) (Borrador), OC X.

Ortega y Gasset, J., «Enviando a Domingo Ortega el retrato del primer toro» (1950), OC X.

Ortega y Gasset, J.«《España como posibilidad» (1910), OC, I.

Ortega y Gasset, J., «La pedagogía social como programa político» (1910), OC II.

Ortega y Gasset, J., «Notas del vago estío» (1925), El Espectador V, OC, II.

Ortega y Gasset, J., «Paisajes ideológicos» (1906), OC VII.

Ortega y Gasset, J., «Para un museo romántico» (1921), El Espectador VI, OC II.

Ortega y Gasset, J., «Verdad y perspectiva» (1916), El Espectador I, OC II.

Ortega y Gasset, J., «Verdad y perspectiva» (1916), El Espectador I, OC II.

Ortega y Gasset, J., «Ideas sobre Pío Baroja» (1916), El Espectador I OC II.

Ortega y Gasset, J., «El tema de nuestro tiempo» (1923), OC III.

Ortega y Gasset, J., «El hombre y la gente» (1949-1950) (Notas), OC X.

Ortega y Gasset, J., «En torno a Galileo» (1933-1947), OC VI.

Ortega y Gasset, J., «Ideas y creencias» (1940), OC V.

Ortega y Gasset, J., «Juan Luis Vives y su mundo» (1940), OC IX.

Ortega y Gasset, J., «Meditaciones del Quijote» (1914), OC, I.

Ortega y Gasset, J., «Prólogo a una edición de sus ‘Obras’» (1932), OC V.

Ortega y Gasset, J., «Velázquez (1943-1950)», OC,VI.

Ortega y Gasset, J., «Algunas notas de José Ortega y Gasset» (1912-1915), Madrid: Revista de Occidente, 156 (1994), 33-54.

Paz, O., 1989: «iNo hay salida?» (1952), Barcelona: Seix Barral.

Quevedo, F. de: 1979: «El sueño de la muerte», Sueños (1627), Obras completas. I, F. Buendía (ed.), Madrid: Aguilar.

Quevedo, F. de: 1979: La cuna y la sepultura (1634), Obras completas. II, Ma- 
drid: Aguilar,

Quevedo, F. de: 1978: Sueños, Madrid: Espasa-Calpe.

Regalado, R. 1990:, El laberinto de la razón: Ortega y Heidegger, Madrid: Alianza.

Reyes, A. 1996: «Visitación» (1951), en Obras completas, México: FCE.

Scherer, G.,1989: «Philosophie des Todes und moderne Rationalität», en Der Tod in Dichtung, Philosophie und Kunst, H. H. Jansen (Hg.), Darmstadt: Steinkopff.

Schumacher, B. N., 2004: Der Tod in der Philosophie der Gegenwart, Darmstadt: Wissenschaftliche Buchgesellschaft.

Silver, Ph., 1978: Fenomenología y razón vital. Génesis de 'Meditaciones del Quijote' de Ortega y Gasset, Madrid: Alianza.

Unamuno, M. de, 2009: «Del sentimiento trágico de la vida» (1912), Obras completas, t. X, Madrid: Fundación José Antonio de Castro.

Wittgenstein, L., 1980: Tractatus lógico-philosophicus (1921), 6.4311, Schriften 1, Frankfurt a. M.,: Suhrkamp.

Antonio Guitiérrez Pozo es catedrático de estética y teoría de las artes en la Facultad de Filosofía de la Universidad de Sevilla.

\section{Lineas de investigación:}

Hermenéutica, Filosofía del arte, Fenomenología, y Ortega y Gasset.

Publicaciones recientes:

- «El arte como irrealización de la realidad y realización de la irrealidad: Arte, ciencia y política en el pensamiento de Ortega y Gasset», Acta Philosophica: rivista internazionale di filosofía, $27 / 1$ (2018), 119-140.

- «La fenomenología de Husserl como razón práctico/existencial: El mundo de la vida como fundamento del proyecto ilustrado husserliano de ciencia estricta», Anales del Seminario de Historia de la FIlosofía, 35/2 (2018), 415-438.

- «El arte como realidad transformada en su verdad. La rehabilitación hermenéutica de la estética en Hans-Georg Gadamer», Kriterion. Revista de filosofía, Vol 59/139 (2018), 5-54.

- «Aproximación a la definición del ensayo como género filosófico: reflexión crítico-literaria sobre el mundo vital mediadora entre arte y ciencia y con voluntad de verdad», Filosofia Unisinos, 20/2 (2019), 128-137.

- «La orientación trascendentalista de la fenomenología de Husserl como ciencia empírico-trascendental de fundamentación absoluta. Por una ilustración sin trascendentalismo?», Aurora. Revista de filosofía, 30/51 (2018), 751-774.

- «Evidencia y ascesis como modos de acceso a la verdad. Teoría y praxis en la evolución de la idea de meditación filosófica», Nuevo Pensamiento, 7/10 (2017), 41-71.

Dirección electrónica: agpozo@us.es 
